\title{
Alegori Kesetiaan Dalam Cerpen Baishui Qingcai (白水青菜) Sup Bening Sawi Hijau Karya Pan Xiangli (潘向黎)
}

\author{
The Allegory of Loyalty in Baishui Qingcai’s (白水青菜) Short Story Sup Bening Sawi \\ Hijau By Pan Xiangli (潘向黎) \\ David Darwin*1, Nuruddin'2, Miftahulkhairah Anwar ${ }^{3}$ \\ ${ }_{1,2,3}$ Program Studi Pendidikan Bahasa, Fakultas Pascasarjana, Universitas Negeri Jakarta, Indonesia \\ e-mail: *1daviddarwin8299@gmail.com, ${ }^{2}$ nuruddin.unj@unj.ac.id, ${ }^{3}$ miftahulkhairah@unj.ac.id
}

\begin{abstract}
ABSTRAK
Artikel ini membahas karya sastra kontemporer Pan Xiangli dalam cerpennya yang berjudul Sup Bening Sawi Hijau. Teori yang akan digunakan adalah teori semiotika untuk menganalisis kehidupan keluarga Cina modern di perkotaan. Analisis semiotika berfokus pada meneliti tanda yang ada dalam sebuah karya sastra yaitu berupa bahasa yang disampaikan. Bahasa merupakan sistem tanda yang memiliki arti dan juga memiliki makna. Dalam sebuah penelitian dengan teori semiotika yang meneliti sistem tanda, setiap tanda yang berupa objek diteliti maknanya yang berdasarkan hubungan antara penanda dan petanda. Sastra adalah salah satu kebudayaan atau ciri khas yang dimiliki seseorang dalam suatu daerah tertentu. Sastra merupakan salah salah satu kebudayaan manusia dan juga membudayakan manusia itu sendiri. Sastra adalah bagian dari hidup manusia. Sastra menggunakan bahasa yang memiliki nilai estetika atau keindahan di dalamnya. Sastra pada prinsipnya adalah sebuah karya imajinatif yang merupakan refleksi dan realitas dari kehidupan si penulis berdasarkan sesuatu yang dilihat dan dirasakan di lingkungannya. Dalam analisis karya sastra ini menggunakan pendekatan semiotika. Istilah semiotika berasal dari kata Yunani Kuno, yaitu semeion yang berarti tanda atau dalam bahasa Inggris. Semiotika merupakan ilmu yang mengkaji tentang tanda-tanda. Ilmu ini menganggap bahwa fenomena sosial atau masyarakat dan kebudayaan di dalamnya merupakan tanda-tanda. Semiotika juga mempelajari sistem-sistem, aturanaturan yang memungkinkan tanda-tanda tersebut mempunyai arti.
\end{abstract}

Kata kunci: Pan Xiangli, Sastra perkotaan, Sastra Cina Kontemporer, Semiotika

\begin{abstract}
This article discusses Pan Xiangli's contemporary literary work in his short story entitled Soup Bening Sawi Hijau. The theory that will be used is the semiotic theory to analyze modern Chinese family life in urban areas. Semiotic analysis focuses on examining the signs that exist in a literary work, namely in the form of the language that is conveyed. Language is a sign system that has meaning and also has meaning. In a study with semiotic theory that examines the sign system, each sign in the form of an object is examined for its meaning based on the relationship between the signifier and the signified. Literature is one of the cultures or characteristics that a person has in a certain area. Literature is one of the human cultures and also the human culture itself. Literature uses a language that has aesthetic or aesthetic value in it. In principle, literature is an imaginative work which is a reflection and reality of the author's life based on something that is seen and felt in his environment. In the analysis of this literary work uses a semiotic approach. The term semiotics comes from the ancient Greek word, namely semeion which means sign or in English. Semiotics is the study of signs. This science considers that social phenomena or society and culture in them are signs. Semiotics also studies the systems, the rules that allow these signs to have meaning.
\end{abstract}

Keywords: Pan Xiangli, Urban Literature, Contemporary Chinese Literature, Semiotics

\section{PENDAHULUAN}

Salah satu sastrawan yang memperhatikan sisi kehidupan para pekerja kerah putih dan tentang kesetaraan antara pria dan wanita adalah Pan Xiangli 潘向黎. Pan Xiangli menulis sebuah cerpen yang berjudul Baishui Qingcai 白水青菜 Sup Bening Sawi Hijau (Untuk selanjutnya 
dalam penulisan penelitian ini penulis akan menggunakan istilah Sup Bening Sawi Hijau). Pan Xiangli lahir pada tanggal 20 Oktober tahun 1966 di Quanzhou 泉州, provinsi Fujian福建, dan kemudian pindah ke Shanghai 上海. Salah satu cerpen karya Pan Xiangli yang dijadikan bahan penelitian adalah cerpen yang berjudul Sup Bening Sawi Hijau. Cerpen dengan latar belakang kehidupan modern di Cina pada tahun 2004 ini menceritakan tentang kehidupan romantika percintaan dalam rumah tangga orang-orang di perkotaan, mengenai orang-orang yang bekerja di perkantoran di Shanghai. Orang Cina menyebut orang-orang tersebut dengan istilah orang-orang yang berkerah putih.

Istilah Bailing 白领 adalah pekerja kerah putih[1]. Pekerja kerah merupakan nama umum para pekerja di Barat yang tidak perlu melakukan banyak pekerjaan secara manual. Para pekerja kerah putih merupakan orang-orang dengan latar belakang pendidikan yang tinggi dan mempunyai pengalaman kerja yang baik, mengacu pada karyawan yang terlibat dalam pekerjaan yang menggunakan pikiran, seperti manajer, teknisi, pejabat pemerintah, dan lain-lain[2]. Para pekerja tersebut mengenakan kemeja putih saat bekerja dan tempat pekerjaan mereka umumnya berada di kantor.

Pekerja kerah putih dengan pakaian cerah muncul pada jalan-jalan di kota metropolitan besar, berjalan dengan bangga, dengan ekspresi acuh tak acuh. Sepatu kulit bersih dan melangkah cepat, mengingatkan orang yang melihatnya bahwa mereka memiliki banyak pekerjaan yang harus dilakukan dan sedang sibuk, komputer, telepon, dan faks adalah mitra kerja terdekat mereka. Ada banyak pesaing, sehingga mereka selalu siap untuk menerima informasi baru, pengetahuan baru, dan terus-menerus meningkatkan diri mereka sendiri. Pekerja kerah putih sekarang telah menjadi kelas profesional yang independen, dan menunjukkan beberapa karakteristik sosial yang berbeda. Di dalam cerpen Sup Bening Sawi Hijau terdapat alegori kesetiaan tentang seorang istri selalu memasak sup untuk suaminya. Alegori merupakan cerita yg dipakai sebagai lambang (ibarat atau kias) mengacu pada perikehidupan manusia yang sebenarnya untuk mendidik (terutama moral) atau menerangkan sesuatu (gagasan, cita-cita, atau nilai kehidupan, seperti kebijakan, kesetiaan, dan kejujuran)[3][4].

Selain itu alegori adalah bahasa kias dalam karya sastra yang memiliki peran yang sangat penting dalam penciptaan citra karya sastra tersebut, karena keindahan karya sastra dapat didukung dengan adanya bahasa kias yang digunakannya[5][6]. Bahasa kias dalam karya sastra dapat memunculkan dan mengembangkan apresiasi dari pembaca. Pembaca dapat masuk dalam suatu karya sastra dengan adanya bahasa kias yang digunakan. Penggunaan bahasa kias atau pemajasan dapat membangkitkan kesan dan suasana tertentu, tanggapan indera tertentu serta memperindah penuturan yang berarti menunjang tujuan-tujuan estetik karya sastra. Sama halnya penggunaan bahasa kias berperan dalam penyampaian maksud seseorang. Kadangkala penafsiran seseorang dapat berbeda dengan maksud yang diungkapkan orang lain melalui gaya bahasa.

Keberadaan majas dapat membuat karya sastra menjadi menarik perhatian, hidup, dan menimbulkan kejelasan gambaran angan[7]. Fungsi bahasa kias adalah menggambarkan sesuatu dalam karya sastra agar menjadi jelas, hidup, intensif, dan menarik. Penggunaan majas dapat ditujukan untuk membangkitkan kesan dan suasana tertentu, tanggapan indera tertentu, serta memperindah penuturan, yang berarti menunjang tujuan-tujuan karya sastra. Dengan demikian fungsi-fungsi yang muncul dari pemanfaatan pemajasan ada bermacam-macam tetapi semua fungsi itu tetap bertujuan untuk membangun nilai estetis dalam karya sastra.

Di dalam cerpen ini juga terdapat kisah tentang kehidupan wanita yang berada di kota juga memperjuangkan hak yang sama dengan pria. Menurut surat kabar Xinhua yang diterbitkan pada tanggal 14 November 2012, istilah Nan nu pingdeng 男女平等 adalah kesetaraan gender yang berarti bahwa pria dan wanita menikmati hak yang sama dan memikul kewajiban yang sama dalam semua aspek baik di bidang politik, ekonomi, budaya, masyarakat dan keluarga[8]. Dalam pasal 48, paragraf 1, Konstitusi Republik Rakyat Cina dengan jelas menyatakan bahwa: "Pria dan wanita di Republik Rakyat Cina memiliki hak yang sama dalam semua aspek kehidupan politik, ekonomi, budaya, sosial dan keluarga". Penulis tertarik untuk mengangkat cerpen karya Pan 
Xiangli ini sebagai bahan untuk penulisan skripsi dengan mengkaji salah satu karya sastra yang berjudul Sup Bening Sawi Hijau.

\section{METODOLOGI PENELITIAN}

Penelitian ini dimulai dengan pengumpulan data dari cerpen Sup Bening Sawi Hijau. Antara lain bentuk teks lengkap asli berbahasa Cina cerpen Sup Bening Sawi Hijau karya Pan Xiangli, profil penulis, jurnal-jurnal berbahasa Cina yang berasal dari National Social Sciences Database[8], buku, artikel ilmiah dan lain sebagainya. Setelah data terkumpul dengan lengkap, penulis akan mulai menerjemahkan cerpen Sup Bening Sawi Hijau ke dalam bahasa Indonesia. Setelah didapatkan penerjemahan yang sesuai, penulis akan memilih teori dan metode yang tepat untuk digunakan dalam penelitian ini.

Setelah semua data sudah selesai disiapkan dan teori maupun metode sudah ditetapkan, penulis mulai menyusun penelitian dalam bentuk dokumen tertulis. Data tambahan akan ditambah selama proses penelitian dan penyusunan dokumen ini. Dalam penelitian perpustakaan, penulis mendapatkan data dari berbagai macam sumber, seperti buku-buku koleksi pribadi dan buku-buku koleksi dari berbagai perpustakaan baik yang berbahasa Indonesia, Inggris maupun yang berbahasa Cina

\section{HASIL DAN PEMBAHASAN}

Analisis semiotik merupakan salah satu teori yang digunakan untuk menganalisis makna karya sastra yang biasa digunakan di bidang sastra Indonesia. Teori ini berfokus pada pengamatan sistem ketandaan. Mengingat hasil karya merupakan suatu sistem yang merupakan tanda berstruktur yang mempunyai makna dan menggunakan bahasa sebagai mediumnya[7]. Bahasa sebagai alat medium karya sastra sudah merupakan suatu sistem semiotik atan ketandaann, yaitu sistem ketandaan yang tentu mempunyai sebuah arti tersendiri. Bentuk bahasa dalam karya sastra berbentuk kata-kata yang merupakan lambang yang tentu mempunyai arti sesuai media komunikasi dalam masyarakat, dalam hal ini berupa bahasa yang digunakan dalam masyarakat, ataupun yang ditentukan oleh norma yang disepakati oleh masyarakat.

Pendekatan yang digunakan dalam penelitian ini adalah pendekatan semiotik Pendekatan semiotik adalah pendekatan yang bertolak dari pandangan bahwa semua yang terdapat dalam karya sastra merupakan lambang-lambang atau kode-kode yang mempunyai arti/makna tertentu. Arti atau makna tertentu di sini berkaitan erat dengan sistem masyarakat. Pengetahuan yang dianut tidak pernah dilepaskan dalam menganalisis dengan menggunakan pendekatan semiotik. Semiotika dapat dijadikan sebuah pendekatan dalam melakukan analisis karya sastra. Seperti yang kita ketahui sebuah karya sastra dapat menyajikan tanda-tanda yang dapat dilihat dari pemakaian bahasa yang digunakan.

Dalam analisis semiotik ini, hal pertama yang perlu diperhatikan adalah pengertian tanda itu sendiri. Untuk pengertian tanda tersebut terdapat dua tingkatan, pertama adalah pengertian berdasarkan konvensi masyarakat berupa arti (meaning), dan yang kedua adalah pengertian berdasarkan konvensi sastra berupa arti dari arti (meaning of meaning), yang selanjutnya disebut makna. Makna dari sebuah karya sastra, dalam hal ini adalah cerpen, tidak hanya ditentukan dari arti bahasanya saja, tetapi juga suasana, perasaan dan unsur-unsur lainnyayang ditimbulkan dalam konvensi sastra. Meskipun sastra dalamsistem semiotik tingkatannya lebih tinggi dari bahasa, namun sastra tidak dapat lepas sama sekali dari sistem bahasa atau konvensi bahasa. Hal ini disebabkan oleh bahasa itu sudah merupakan tanda yang mempunyai arti berdasarkan konvensi tertentu[7].

Analisis semiotika dalam skripsi ini difokuskan pada pembahasan sistem tanda, bahasa kiasan, dan gaya bahasa. Semua ini ditujukan untuk memahami tanda alegori kesetiaan dan kesetaraan pria dan wanita dalam cerpen Sup Bening Sawi Hijau. Dalam kajian semiotik, tanda merupakan konsep utama yang dijadikan sebagai bahan analisis di mana di dalam tanda terdapat makna sebagai bentuk interpretasi pesan yang dimaksud. Secara sederhana, tanda cenderung 
berbentuk visual atau fisik yang ditangkap oleh manusia. Dan juga merupakan konsep pemikiran dari orang yang menggunakan tanda dan menurunkannya ke suatu makna tertentu atau makna yang ada dalam benak seseorang tentang objek yang dirujuk sebuah tanda[9]

Dengan metode semiotika penulis mengambil beberapa bentuk analisis dari cerpen Sup Bening Sawi Hijau tersebut. Bentuk analisis yang pertama adalah dalam cerpen tersebut nyonya rumah diperankan oleh wanita itu, umurnya sekitar 40-an sudah menikah dan memiliki seorang anak laki-laki yang tampan. Suaminya adalah seorang pekerja kantoran, awalnya bekerja di kantor pemerintahan dan kemudian berbisnis dan memilki bisnis yang sangat sukses hidup serba berkecukupan, wanita itu rajin dan juga setia memasak semangkop sup yang sangat enak menurut pria itu dan setia menunggu suaminya untuk pulang makan malam bersama setelah pria itu seharian bekerja. Hal ini didukung oleh kutipan cerpen sebagai berikut:

\section{他就自己从瓦罐里舀了小半碗汤。清清的汤色, 不见油花, 绿的是} 青菜, 白的是豆腐, 还有三五粒红的枸杞, 除了这些再也不见其他东西。 但是味道真好。说素净, 又很醇厚; 说厚, 又完全清淡; 说淡, 又透着清 甜; 而且完全没有一点味精、鸡精的修饰, 清水芙蓉般的天然。

Pria itu menyendok setengah mangkuk sup dari dalam guci. Warna kuah yang bening, tidak terlihat buih minyak, yang berwarna hijau adalah sawi hijau, yang berwarna putih adalah tahu, masih terdapat tiga sampai lima butir goji yang berwarna merah, selain sawi hijau, tahu dan goji ini tidak terlihat makanan yang lainnya. Tetapi rasanya enak. Dikatakan murni sayuran, juga sangat kental; Dikatakan kental, sepenuhnya hambar; Dikatakan hambar, terlihat bening dan manis; Lagipula sepenuhnya tidak ditambah vetsin ataupun esensi ayam, benar-benar alami seperti bunga kembang sepatu yang baru saja keluar dari air jernih, sederhana dan cerah, tanpa hiasan apa pun.

Pria itu juga pernah memuji masakan wanita itu sangat enak pada saat membuka tutup guci tanah liat melihat warna yang indah, setelah setengah panas, kuah sup pertama masuk mulut, jernih, harum, manis, licin ...... Pada gilirannya bermekaran di lidah, serat-serat sawi hijau yang berada di dalam mulut sangat lembut pada gigi, membuat perlawanan yang menyenangkan, belaian lembut tahu meluncur nyaman di tenggorokan, dan sup meluncur mengikuti pencernaan, sepanjang jalan lancar, selalu nyaman menempel di dalam perut, Dikatakan murni sayuran, juga sangat kental; Dikatakan kental, sepenuhnya hambar; Dikatakan hambar, terlihat bening dan manis; Lagipula sepenuhnya tidak ditambah vetsin ataupun esensi ayam, benar-benar alami seperti bunga kembang sepatu yang baru saja keluar dari air jernih, sederhana dan cerah, tanpa hiasan apa pun. Hanya seteguk saja, seluruh perut sangat nyaman, memulihkan organ sensorik yang kaku seharian, ekpresi wajah berubah, seperti sebuah cangkang yang tipis pecah diketuk, setiap tekstur semua otot semuanya mulai hidup. Benar-benar sup yang luar biasa! Sup yang sangat enak bahkan bisa mengalahkan masakan sup dari keluarga yang paling pandai memasak sup sekalipun. Hal ini didukung dari kutipan cerpen di bawah ini:

“喝了。到底怎么做的? 人家都说老王家汤馆好, 我看就是那里都 喝不到这么好的。说给我听听。”

“Sudah. Sebenarnya bagaimana memasaknya? Orang-orang mengatakan restoran sup keluarga Wang enak, aku melihat disana tidak bisa minum sup yang begini enak. Ayo katakan padaku."

Keluarga mereka adalah keluarga emas putih yang membuat orang lain iri. Arti emas putih adalah kaya dan berdasi putih, arti berdasi putih adalah mengacu pada berpendidikan tinggi, berbudi luhur dan taat peraturan, menghasilkan uang berdasarkan pengetahuan dan kecerdasan, bukan orang kaya baru yang di tangannya memakai beberapa perhiasan cincin permata. Tanpa diduga datanglah seorang wanita yang bernama Dudu yang berusaha untuk merebut hati pria itu. 
Akan tetapi Dudu bukan ingin merebut harta dari pria itu karena ia berasal dari keluarga yang kaya raya. Hal ini dapat dibuktikan dari kutipan cerpen di bawah ini:

嘟嘟的出现完全是一个意外。起初他觉得这是个稚气未脱的女孩 子, 像个水晶花瓶一样好看又透明, 而且不实用。等到看出她的企图还觉 得有些好笑一一这不是胡闹吗? 要不是她是他的下属, 本来可以叫他叔叔 的。当然心里还是有点高兴的, 很隐蔽但是很真切, 这可是一个比自己小 20岁的女孩子啊, 又漂亮, 而且出身很好, 父亲是大律师, 母亲是名医, 家里本来要送她去剑桥留学的。这样的女孩, 没有任何为了钱而接近男人 的嫌疑。

Kemunculan Dudu sepenuhnya adalah sebuah kecelakaan. Awalnya pria itu merasa ini adalah seorang anak gadis yang belum dewasa, cantik dan bening seperti sebuah vas bunga kristal, lagi pula tidak praktis. Menunggu sampai terlihat niatnya masih merasa sedikit lucu --- Bukankah ini namanya cari perkara? Jika bukan dia adalah bawahan pria itu, sebenarnya bisa memanggil pria itu paman. Tentu saja, hati masih sedikit senang, sangat tersembunyi namun sangat nyata, ini hanyalah gadis yang berusia 20 tahun lebih muda dari dirinya, cantik, lagipula terlahir sangat baik, ayahnya adalah seorang pengacara besar, ibunya adalah seorang dokter terkenal, keluarganya sebenarnya ingin mengirimnya untuk belajar di Cambridge. Gadis yang demikian, tidak memiliki kecurigaan apa pun mendekati pria demi uang.

Walaupun pria itu sudah tergoda dengan Dudu dan tidak pernah pulang lagi untuk makan malam, akan tetapi wanita itu masih dengan setia memasak semangkok Sup Bening Sawi Hijau untuk di hidangkan kepada pria itu dan menunggunya pulang. Saat pria itu mencari alasan untuk tidak pulang wanita itu hanya bisa diam dan pasrah. Hal ini terlihat dalam kutipan cerpen di bawah ini:

她沉默，就像他每次说不回家吃饭时一样，绵长而细密的沉默，那 重量使他感到压迫, 但是不敢挂电话。最后, 她说: “这样吧, 你要回来 吃饭就打电话。”

Wanita itu terdiam, sama seperti pria itu setiap kali mengatakan tidak pulang ke rumah untuk makan, diam yang tersembunyi dan memanjang, perasaan berat itu membuat pria itu merasa tertindas, tetapi tidak berani menutup telepon. Akhirnya, wanita itu berkata "Begini saja, bila kamu mau pulang untuk makan maka menelepon"

Pria itu sudah tidak pernah pulang lagi dan telah tinggal dengan selingkuhannya Dudu, akan tetapi pria itu setiap makan tetap saya merindukan semangkok sup yang sangat enak dan bisa bisa membangkitkan gairah dan semangat serta mengaktifkan kembali saraf-saraf yang telah lelah karena seharian bekerja. Sup dari wanita itu benar-benar selalu menghantui pria itu. Hal ini dapat dibuktikan dari kutipan cerpen di bawah ini:

他们都不愿意想起一个人，一个女人。但她总是在最不经意的时候 出现。就像一个狡猾的债主, 从来不会拦在大路中间, 让你可以放心地开 车回家, 回到家门口, 也不会看到有人气势汹汹地站在那里。于是你松了 一口气, 走进房间, 打开灯, 却猛然一惊, 角落里赫然站着一个人, 正是 躲也躲不掉的那一个。

Mereka enggan memikirkan seseorang, seorang wanita. Tetapi wanita itu selalu muncul di saat yang paling tidak disengaja. Seperti seorang pemberi piutang yang licik, sejak dulu tidak akan menghalangi di tengah jalan besar, membuat kamu bisa tenang mengendarai mobil pulang ke rumah, setelah sampai di rumah, juga tidak akan melihat ada orang berdiri di sana dengan agresif. Кетudian kamu lega, memasuki kamar, 
menyalakan lampu, sebaliknya tiba-tiba terkejut, seseorang berdiri mengesankan di sudut, benar-benar itu yang bersembunyi pun tidak bisa bersembunyi.

Hanya karena Semangkok Sup Bening Sawi Hijau kehidupan pria itu dan Dudu tidak bahagia, bahkan Dudu telah bersusah payah memasak masakan dari resep buku Haruki Murakami sekalipun masih tidak bisa mengalahkan semangkok Sup Bening Sawi Hijau yang dimasak oleh wanita itu. Kemudian Dudu berusaha menemui wanita itu dengan maksud meminta resep semangkok sup yang sangat di idam-idamkan pria itu. Hal ini dapat dibuktikan dari kutipan cerita di bawah ini:

她打开了门, 一个年轻女孩出现在她面前, 有着紧绷的脸项和鲜嫩 的皮肤的女孩。她用微笑的眼神发问，这个女孩子说：“叫我嘟嘟吧，我 是你丈夫的朋友。”

Wanita itu membukakan pintu, seorang gadis muda muncul di hadapan wanita itu, gadis yang pipinya kenyal dan kulitnya lembut dan segar. Wanita itu bertanya menggunakan pandangan yang tersenyum ringan, gadis itu menjawab: "Panggil saja aku Dudu, aku adalah teman suamimu."

Setelah melihat Dudu wanita itu langsung mengerti. Mengerti gadis ini adalah siapa. Wanita itupun mempersilakan Dudu masuk rumah. Seperti seorang wanita yang sopan memperlakukan selingkuhan suaminya. Dudupun ingin mencari dari wajah wanita itu apakah tidak menyukainya, akan tetapi Dudu tidak dapat menemukannya. Dudu ingin merasakan semangkok Sup Bening Sawi Hijau yang sangat diinginkan pria itu. Terlihat dalam kutipan cerpen di bawah ini:

她让嘟嘟参观了他们的家, 但是没有让她看卧室。然后她们坐了下 来，喝着茶，一时都找不到话题。嘟嘟说：“谢谢你接待我。其实我今天 来, 一是想看看你是什么样子的, 另外就是想吃你做的饭。”看到她脸上 的惊讶, 嘟嘟急忙解释: “我总听他夸你是个高手, 最简单的菜都能做得 最好吃, 真的很好奇。”

Wanita itu membiarkan Dudu meninjau rumah mereka, tetapi tidak membiarkan Dudu melihat kamar tidurnya. Kemudian mereka duduk, minum teh, sesaat tidak dapat menemukan topik pembicaraan. Dudu, berkata: "Terima kasih telah menerimaku. Sebenarnya aku hari ini datang, pertama adalah ingin melihat wajah kamu bagaimana, kedua adalah ingin makan masakanmu." Melihat wajah wanita itu terkejut, Dudu segera menjelaskan: "Aku selalu mendengar suamimu memuji kamu seorang master, makanan yang paling sederhana bisa memasaknya paling enak, benar-benar sangat penasaran."

Dudu kemudian bisa merasakan semangkok Sup Bening Sawi Hijau yang sangat dirindukan oleh pria itu, dan menanyakan kepada wanita itu bagaimana cara membuat sup tersebut. Setelah dijelaskan oleh wanita itu Dudu baru tahu bahwa untuk mendapatkan seangkok sup yang begitu lezat membutuhkan kesetiaan, kesabaran dan pengorbanan yang luar biasa. Hal ini dapat dibuktikan dari kutipan cerpen berikut ini:

女主人停了一下, 好像微微地叹了一口气。然后说: “要准备很 多东西。上好的排骨，金华火腿，苏北草鸡，太湖活虾，莫干山的笋， 蛤蜊, 蘑菇, 有螃蟹的时候加上一只阳澄湖的螃蟹, 一切二, 这些东西 统统放进瓦罐，用慢火照三、四个钟头，水一次加足，不要放盐，不要 放任何调料。”

Nyonya rumah berhenti sejenak, seperti setengah mendesah. Kemudian berkata: "Harus mempersiapkan banyak bahan makanan. Tulang iga yang bagus, ham di kota Jinhua, ayam kampung dari Subei, udang hidup danau Taihu, rebung gunung Mogan, kerang, jamur, ketika ada kepiting ditambah seekor kepiting danau Yangcheng, 
dipotong menjadi dua, bahan-bahan makanan ini semuanya dimasukkan ke dalam guci tanah liat, dipanaskan dengan api kecil selama 3-4 jam, ditambah air secukupnya, jangan memasukkan garam, jangan memasukkan bumbu lain apapun."

Setelah pria itu pergi dengan Dudu selama setengah tahun, akan tetapi dengan kesetiaan yang begitu dalam. Wanita itu masih saja terus memasak semangkok Sup Bening Sawi Hijau sebagai tanda kesetiaannya terhadap pria itu, walaupun sebenarnya wanita itu tidak tahu kapan pria itu akan pulang ke rumah lagi untuk meminum semangkok sup tersebut. Terlihat dari kutipan cerpen di bawah ini:

“你是说他没有回来吃晚饭吧？是啊，都半年了，不过我还是每天 这样准备, 说不定哪天他突然回来吃呢? 再说我都习惯了, 守着一罐汤 , 也有点事情做。”

"Maksudmu suami tidak pulang untuk makan malam ya? Ya, sudah setengah tahun, tetapi aku masih mempersiapkannya setiap hari, barangkali pada suatu hari suami tiba-tiba pulang ke rumah untuk makan? Sebenarnya aku sudah terbiasa, menjaga seguci sup, dengan demikian bisa melakukan sedikit hal."

Dari kutipan naskah di bawah ini dapat terlihat perbedaan kesetiaan wanita itu dan Dudu terhadap pria itu, seorang wanita yang sudah di tinggalkan oleh suaminya sekian lama akan tetapi masih setia untuk menunggu dan memasak sup kesukaan suaminya, sedangkan Dudu yang sudah diberitahu resep sup yang paling dicari oleh laki-laki itu namun Dudu tidak bersedia melakukannya. Hal ini didukung oleh kutipan cerpen berikut ini:

嘟嘟偏着头, 认真地想了想, 说: “我也可以的, 但是不必了。”她 说完, 就站起来走了, 走到门口, 她站住, 回头一笑, 说: “我不是你。 "

Dudu memiringkan kepalanya, berpikir dengan serius, lalu berkata, "Aku juga bisa, tetapi sudah tidak perlu." Dudu selesai bicara, lalu berdiri dan berjalan, berjalan sampai di depan pintu, Dudu berhenti, menolehkan kepala sambil tersenyum, berkata: "Aku bukan kamu."

Setelah lewat beberapa waktu pria itupun pulang lagi ke rumah, seperti biasa wanita itu tetap melayani pria itu untuk makan dan masih menghidangkan semangkok sup tersebut. Akan tetapi sup yang dihidangkan bukanlah sup seperti yang dulu lagi. Hal ini dapat diketahui dari kutipan berikut ini:

“怎么这么难喝？以前的汤不是这样的! ”他委屈地抗议。
“Kenapa begitu tidak enak? Sup yang dulu tidak begitu!”Pria itu protes mengeluh.

Seorang wanita yang begitu mencintai suaminya, akan tetapi pria itu tidak bisa merasakan dan menghargai semua pengorbanan dan kesetiaan yang telah dilakukan oleh wanita itu. Pepatah Indonesia mengatakan "Air susu dibalas dengan air tuba" Setelah pria itu kembali lagi wanita itu memberikan semangkok sup yang tidak seperti ia masak selama ini, seolah-olah wanita itu ingin berbicara lebih sup itu bahwa ia bukanlah wanita yang seperti dulu lagi, maka sebagai seorang yang sudah dikhianati maka sudah tentu cinta dan kesetiaannya akan berubah tidak seperti dulu lagi. Hal ini dapat dibuktikan dari petikan cerpen berikut ini:

她尝了一口，然后说：“白水青菜，就是这样的。你要它什么味道?

Wanita itu mencicipinya kemudian berkata: "Sup bening sawi hijau, ya begitu. Kamu menginginkan dia seperti apa?" 
Setelah selesai makan wanita itu mengatakan satu hal yang penulis bisa menarik sebuah kesimpulan bahwa wanita itu ingin mengatakan bahwa "Jika kamu bisa melakukan hal ini saya juga bisa melakukannya" Ia masih setia tidak minta cerai dari pria itu namun wanita itu ingin meminta kesetaraan antara pria dan wanita. Wanita tidak mesti hanya di rumah saya memasak dan mengurus rumah. Seorang wanita pun bisa melakukan apapun yang bisa pria lakukan. Hal ini dapat dibuktikan dari kutipan cerpen berikut ini:

吃完最后一口，她把所有的碗碟都收回托盘里，然后正视着他，说 : “我们家以后可能要雇一个钟点工, 我找到工作了, 家里这么多事。”

Setelah selesai makan suap yang terakhir, wanita itu membereskan seluruh piring ke dalam nampan, kemudian menatap pria itu, berkata: "Rumah kita nanti mungkin harus menyewa pembantu selama satu jam, aku mendapat pekerjaan, urusan di dalam rumah sangat banyak."

Dalam penulisan novel ini bukanlah membuat orang kagum dengan kesetiaan wanita itu, namun malah sangat mengerikan, wanita itu memberontak dalam diam. Kehadiran nyonya rumah selain di awal dan akhir cerita, dibagian lainnya tidak diceritakan. Namun ketika membacanya, seolah-olah selalu hadir disetiap bagian cerita. Begitu seorang wanita dikhianati dan dikecewakan maka ia akan berubah 360 derajat dan akan menuntut persamaan derajat dan haknya sebagai seorang wanita. Supaya laki-laki itu merasakan penyesalan, menyadari penyesalan, dan merasakan kehampaan rasa tanpa cinta.. Oleh karena itu, nyonya rumah adalah karakter nomor satu dalam novel ini. Pembuktiannya dapat dilihat dari kutipan cerpen berikut ini:

但是，她没有反击，她甚至没有说什么。她只是看了他一眼。这 一眼, 让他真正开始感到自己的愚蚌。那目光很清澈, 但又幽深迷离, 好 像漆黑的夜里，四下无人的废园子中井口审出来的白气，让人感到寒意。

Tetapi, wanita itu tidak menyerang balik, wanita itu bahkan tidak mengatakan apapun. Wanita itu hanya memandangnya sekilas. Padangan sekilas ini, membuat pria itu benar-benar mulai merasakan kebodohan dirinya sendiri. Sorot mata itu sangat jernih, tetapi mengaburkan dengan sangat mendalam, seperti asap putih yang meluncur keluar dari mulut sumur di tengah taman yang tidak ada orang di sekitarnya di malam yang gelap, membuat orang merasakan makna yang dingin.

Setiap hasil karya sastra sudah pasti mempunyai dasar atau tema yang merupakan sasaran tujuan, namun isi tema itu sendiri tidak mudah ditunjukkan. Tema dalam suatu cerita haruslah dipahami dan ditafsirkan melalui cerita unsur-unsur pembangun cerita yang lain. Untuk menemukan tema dalam sebuah karya fiksi, yang harus dilakukan adalah menyimpulkan dari keseluruhan cerita tersebut, tidak hanya berdasarkan bagian-bagian tertentu dalam cerita. Tema, dengan demikian, dapat dipandang sebagai dasar cerita, gagasan dasar umum sebuah karya fiksi.

Sebagai sebuah makna, pada umumnya tema tidak dilukiskan, paling tidak pelukisan yang secara langsung atau secara khusus. Kehadiran tema adalah terimplisit dan masuk dalam keseluruhan cerita, dan inilah yang menyebabkan kecil kemungkinan pelukisan secara langsung. Hal ini juga merupakan tidak mudah dalam penafsiran suatu tema. Penafsiran tema (utama) harus berdasarkan oleh pemahaman cerita secara keseluruhan. Namun adakalanya dapat juga ditemukan adanya kalimat-kalimat atau alinea-alinea, percakapan tertentu yang dapat ditafsirkan sebagai sesuatu yang mengandung tema pokok[10].

Setelah penulis membaca serta menganalisis cerita cerpen Sup Bening Sawi Hijau dengan teori semiotika maka penulis berpendapat bahwa tema dari cerpen ini adalah: tema yang pertama adalah tentang kesetiaan seorang wanita. Cerita pendek Sup Bening Sawi Hijau ini menceritakan seorang istri yang ditinggalkan oleh suaminya karena orang ketiga, akan tetapi wanita itu tidak pernah putus asa dan berhenti memasak sup kesukaan pria itu, dan setiap sore mempersiapkan pelan-pelan semangkok sup sambil menunggu pria itu untuk pulang makan malam bersama. Hal ini dilakukan bukan hanya satu atau dua hari, akan tetapi wanita itu lakukan setiap hari sampai 
pada akhirnya pria itu pulang ke rumah. Wanita itu melakukan pemberontakan secara diam-diam dengan tidak memberikan sup yang biasa ia berikan kepada pria itu.

Tema lainnya adalah tentang kesetaraan antara pria dan wanita. Ketika pria itu pulang maka wanita itu mengatakan dengan sebuah bahasa isyarat bahwa mulai saat ini harus mempekerjakan pembantu rumah tangga karena wanita itu akan keluar rumah untuk bekerja, melakukan hal yang sama seperti yang pria itu lakukan. Tidak hanya setiap hari di rumah untuk mengurus rumah tangga, maka bisa dikatakan bahwa wanita itu menuntuk persamaan haknya agar setara dengan pria itu

\section{SIMPULAN}

Cerpen karya Pan Xiangli yang berjudul Sup Bening sawi Hijau pertama kali diterbitkan pada tahun 2004. Setelah empat tahun diterbitkan, yaitu pada tahun 2007, cerpen yang berjudul Sup Bening Sawi Hijau ini mendapatkan apresiasi dari pembaca yang begitu luar biasa dan bahkan mendapatkan berbagai penghargaan sekaligus, termasuk memenangkan Penghargaan Sastra $L u$ Xun 鲁迅 ke-4. Pan Xiangli merupakan seorang penulis paling terkenal untuk sastra kontemporer Cina saat ini.

Lahir pada tahun 1966, pada awal Revolusi Kebudayaan, saat itu pertempuran merajalela, dan pendidikan tumbang. Pan Xiangli pergi dari kota kelahirannya dan orang tuanya merasakan munculnya kegelapan hidup dalam serba kekurangan, tapi mereka sangat yakin bahwa segalanya akan berlalu, berharap akan datangnya terang, sehingga mereka membiarkan putri mereka pergi ke Shanghai menuju jalan terang, penuh dengan harapan. Meskipun ia pindah ke Shanghai sejak usia dua belas tahun, tetapi Pan Xiangli mengidentifikasi dirinya sebagai penulis Fujian dan hanya tinggal jauh di luar saja.

Banyak kritikus mengatakan bahwa karya-karya Pan Xiangli memiliki gaya tersendiri dalam menulis. Hampir setiap karyanya menceritakan tentang kehidupan dan romantika percintaan orang-orang kerah putih yang ada di kota modern, seperti mencerminkan dirinya yang lahir di kota kecil kemudian pindah dan hidup di kota besar. Tapi kenyataan sebenarnya adalah dia hanya ingin menyampaikan yang sebenarnya terjadi dalam kehidupan orang-orang saat ini.

\section{REFERENCES}

[1] I. R. Suhandra, "Studi Komparatif Makna Konotasi Warna Dalam Budaya Masyarakat Barat Dan Masyarakat Suku Sasak Lombok Indonesia," Cordova J. Lang. Cult. Stud., vol. 9, no. 1, pp. 17-38, 2019, doi: 10.20414/cordova.v9i1.1774.

[2] A. Ayuna, "Pekerja Kerah Putih dan Kerah Biru Apa Perbedaannya?," Insight Talenta, 2019. https://www.talenta.co/blog/insight-talenta/pekerja-kerah-biru-dan-pekerja-kerahputih-2/.

[3] F. Angela Nai, "Fungsi Dan Makna Alegori Dalam Syair Su' I Uwi Sastra Lisan Ngadha , Flores , Nusa Tenggara Timur," J. Lazuardi, vol. 3, no. 1, pp. 367-378, 2020.

[4] R. Rinaldi, A. C. Tamsin, and Z. Zulfadhli, "Gaya bahasa lirik lagu band betrayer album the best of," J. Pendidik. Bhs. dan Sastra Indones., vol. 1, no. 1, pp. 214-221, 2012.

[5] F. Lafamane, "Kajian Stilistika (Komponen Kajian Stilistika)," osfpreprints, doi: 10.31219/osf.io/5qjm4.

[6] D. Septiani, "Majas dan Citraan dalam Puisi 'Mishima' Karya Goenawan Mohamad (Kajian Stilistika)," J. Sasindo Unpam, vol. 8, no. 1, pp. 12-24, 2020.

[7] R. D. Pradopo, "Semiotika: Teori, Metode, Dan Penerapannya Dalam Pemaknaan Sastra," J. Hum., 1999.

[8] H. Evans, The Intimate Individual: Perspectives from the Mother-Daughter Relationship in Urban China. 2012.

[9] R. Kriyantono, "Teknik Praktis Riset komunikasi - Rachmat Kriyantono, S.Sos., M.Si Google Books," Kencana Prenada Media Group, 2006. . 
[10] B. Nurgiyantoro, "Teori pengkajian fiksi / Burhan Nurgiyantoro," in Teori Pengkajian Fiksi, 2015. 